\title{
Prevalence of Parkinson's disease in Estonia
}

Pille Taba, Toomas Asser

Department of Neurology and Neurosurgery, University of Tartu, Tartu, Estonia

\begin{abstract}
Objectives - To investigate the prevalence of idiopathic Parkinson's disease (PD) in the Tartu district of South Estonia, with a population of 153,240 on prevalence day, January $1^{\text {st }}$, 1996. Methods - The community-based method of case ascertainment was used, followed by neurologic examination. Results - The age-adjusted prevalence was 152 per 100,000 population, 159 for urban and 139 for the rural group, 154 for men and 153 for women. The age-specific prevalence increased from 22 per 100,000 population in the age group 40-49 years up to 1232 per 100,000 population in the age group 70-79 years. The mean age of PD patients was 71.4 years, the mean age at onset of the symptoms - 66.9 years. Conclusions - When comparing the prevalence rates with other studies of Caucasian populations in Europe, the results are similar except for slightly but not significantly higher prevalence rates in the urban population in Estonia.
\end{abstract}

Key Words: Parkinson's disease, epidemiology, prevalence

\section{Introduction}

Parkinson's disease (PD) is one of the most common neurodegenerative diseases throughout the world. In epidemiological surveys, the age-adjusted prevalence rates range from 18 to 207 per 100,000 population, being somewhat different depending on the case ascertainment methodology and racial factors (1-3). In community-based studies the ageadjusted prevalence rates in the Caucasian populations range from 56 to 190 (1-13) while in door-to-door studies they are from 90 to 199 per 100,000 population (1-3, 14-15). For the Asian populations, the prevalence rates are somewhat lower, being from 61 to 100 by the community-based method of case ascertainment $(1-3,16-17)$ and from 18 to 148 by the door-to-door method (1-3, 18-19). Only a limited number of studies are available about the occurrence of PD in the African populations; most of them are hospital-based investigations. The prevalence rates for African blacks in community-based studies range from 4 to 31 per 100,000 population $(1,3,20)$.

The purpose of our community-based prevalence study was to assess the occurrence of PD both in the urban and rural area of South Estonia. Simultaneously the results of the study would provide an audit of care need. Patient data could be used in future investigations concerning PD as well as in planning the allotment of health care resources in the district.

\section{Patients and methods}

Estonia is the northernmost Baltic country with a population of 1.5 million inhabitants. The area of this epidemiological survey was the Tartu district in South Estonia (Fig. 1) with a total population on prevalence day, January $1^{\text {st }}, 1996$ of 153,240, with 103,424 inhabitants living in the urban area (the city of Tartu), and 49,816 inhabitants in rural areas; 71,139 (46\%) men and 82,101 (54\%) women. Population data was obtained from the Statistical Office of Estonia (21). 


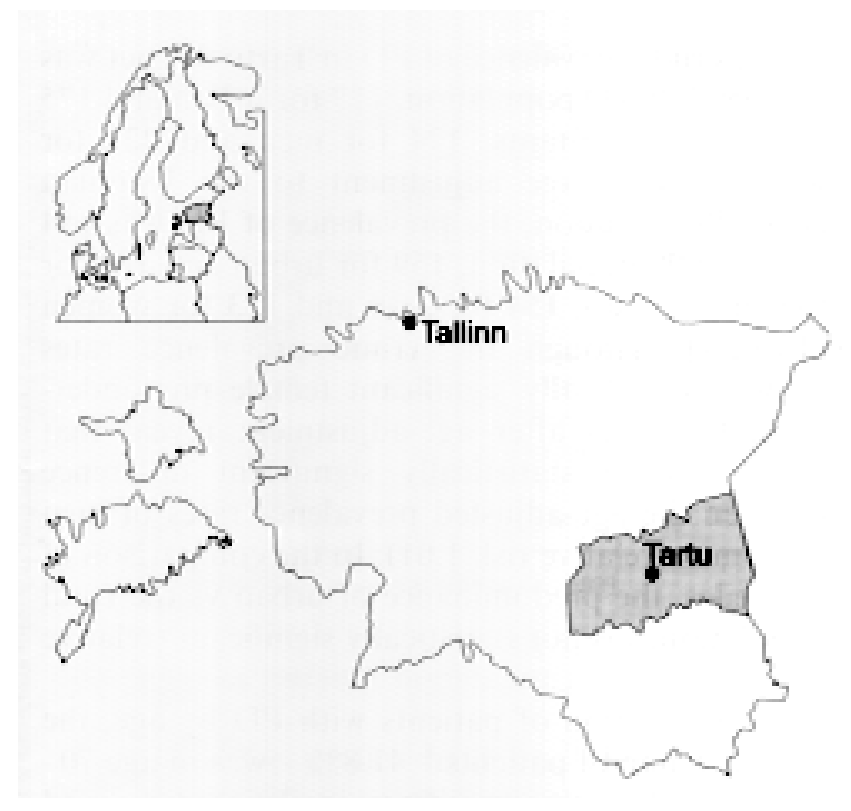

Figure 1. Geographic location of the study population in South Estonia. The small map shows Nordic and Baltic countries, the detailed map shows area of the investigation (Tartu district).

Estonia has a developed medical care and registration system. Health care is universally available and uniformly delivered. All patients are registered by any family doctor, and those with suspected chronic neurological diseases are referred to a neurologist. Tartu is a suitable place for epidemiological studies as the Department of Neurology and Neurosurgery of Tartu University, the only teaching neurological hospital in Estonia, is the neurological centre for the region.

Information from all available sources has been used for case ascertainment. People diagnosed with PD, parkinsonian and parkinson-like syndrome or undefined tremor were identified as patients with possible PD. Cases of other extrapyramidal diseases and essential tremor with fully evident diagnosis were excluded on the basis of case reports. The outpatient and hospital records of the Department of Neurology and Neurosurgery of Tartu University over the past 10 years were reviewed. All 72 general practitioners and family doctors, working in the investigation area, were contacted and asked to report about the patients under their care. There was no any private practitioner working this time as family doctor or general practitioner in the area. Four members of the staff of the Department of Neurology and Neurosurgery who had simultaneously private practice were asked about the cases of possible PD; there were no neurologists in private practice outside the hospital. For case finding, 11 nursing homes and hospitals in Tartu district were visited. All patients living in nursing homes and hospitals were visited personally as the institutionalization could be a consequence of a disability related to PD $(22,23)$. The membership list of the Tartu Parkinson's Disease Society was obtained. The Sick Fund which provides health insurance supplied the data about prescriptions for antiparkinsonian drugs. Information on migration and death certificates was provided by the Tartu Population Registry. Data about patients was requested regularly every year from 1995 to 1999.

All the patients in the current study were interviewed and examined by one of the authors; if diagnostic problems occurred a senior neurologist participated in the examination and diagnostic decision. Home visits were proposed to severely disabled people. The structured questionnaire included details of the medical history, living conditions, occupation, family history and medication. The neurological examination included the Unified Parkinson's Disease Rating Scale (UPDRS) Version 3.1 (24) and 
Hoehn-Yahr Rating Scale (25). Interviewing and examining participants began in 1995 and continued until 1999.

The diagnostic criteria set of the United Kingdom Parkinson's Disease Society Brain Bank was used in the Tartu study for verifying the diagnosis of PD (26). A diagnosis of PD was established in a patient based on the presence of bradykinesia and at least one of the following symptoms: resting tremor, rigidity, and impaired postural reflexes, if no other cause of parkinsonism was apparent. Unilateral onset, progressive course, persistent asymmetry, good response to levodopa, severe levodopa-induced dyskinesia, and clinical course of 10 or more years in duration were considered as helpful in diagnosis.

Secondary parkinsonian syndromes were diagnosed according to the history (strokes, use of the neuroleptic drugs, head injury, brain tumor, infection). Parkinson plus syndromes were diagnosed if the parkinsonism was in association with additional neurological signs (prominent oculomotor palsy, cerebellar or pyramidal signs, orthostatic hypotension, amyotrophy etc.) indicating the degeneration of defined neuroanatomical systems (27). The clinical diagnosis of essential tremor was arrived upon when postural or kinetic persistent tremor in the head or upper extremities was observed without other abnormal neurologic signs (28). Those patients categorised as not having the syndrome of PD and those with isolated tremor were fully recorded and examined but excluded from the prevalence estimates.

The statistical analysis was performed with the SAS system for Windows, version 6.12 (Cary). The 95\% confidence intervals (CI) for rates were calculated assuming the Poisson distribution of observed cases. The differences between groups were statistically evaluated using the t-test and chi-square test. A p value less than 0.05 was considered significant. Prevalence rates were adjusted for gender and age to the 1989 population in Estonia using the direct method of standardization.

The Ethics Review Committee of Clinical Research Studies of University of Tartu approved the study.

\section{Results}

Information was collected from the previously noted sources about 384 patients with possible PD. Sixteen patients died and five patients moved from the district before prevalence day, January $1^{\text {st }}$, 1996. Eleven patients had some other disease but no evidence of akinetic rigid syndrome or tremor, and 31 patients had essential tremor. From the whole clinical group with parkinsonism, 51 patients (16\%) did not have PD: 17 presented with secondary parkinsonism, 27 with parkinson plus syndrome, and seven with undefined parkinsonism (if the clinical syndrome did not satisfy the assessment criteria of PD and a firm diagnosis for any definite type of parkinsonism was not possible).

Altogether 270 patients, 88 men and 182 women as having PD, formed the basis of the prevalence data. From the study group $91 \%$ were examined clinically, 16 patients refused and eight died between the prevalence day and clinical examination. All 24 of these patients had case note data recorded by a neurologist providing a firm diagnosis of PD. On prevalence day, January $1^{\text {st }}, 1996$, from the final patient group with idiopathic PD $68 \%$ lived in urban and $32 \%$ in rural areas; $33 \%$ were men and $67 \%$ women.

On the evaluation of clinical severity and disability by Hoehn-Yahr Rating Scale, $54.9 \%$ of the PD patients were categorized as stage I or II, $26.2 \%$ as stage III, $16.4 \%$ as stage IV and $2.5 \%$ as stage V. The mean score of UPDRS was $67.0 \pm 23.4$; among this the mean score of part II (Activities of Daily Living) was 16.9 \pm 8.0 , and the mean score of part III (Motor Examination) was 44.4 \pm 14.9 . The total UPDRS score was $\leq 50$ in $29.2 \%$ of PD patients, $51-100$ in $63 \%$, and $\geq 101$ in $7.8 \%$ of the patients. 


\begin{tabular}{lcccc}
\hline & Population & Number of cases & Prevalence rate & $95 \%$ CI \\
\hline Total & 153,240 & 270 & 152 & $128-176$ \\
Men & 71,139 & 88 & 154 & $130-178$ \\
Women & 82,101 & 182 & 153 & $128-177$ \\
Urban & 103,424 & 183 & 160 & $135-185$ \\
Urban men & 47,545 & 60 & 171 & $146-197$ \\
Urban women & 55,879 & 123 & 157 & $133-182$ \\
Rural & 49,816 & 87 & 139 & $116-162$ \\
Rural men & 23,594 & 28 & 128 & $106-150$ \\
Rural women & 26,222 & 59 & 145 & $122-169$ \\
\hline
\end{tabular}

Table 1. Age-adjusted prevalence rates of PD (per 100,000)

\begin{tabular}{|c|c|c|c|c|c|c|c|c|}
\hline \multirow[b]{2}{*}{$\begin{array}{l}\text { Age } \\
\text { group }\end{array}$} & \multicolumn{3}{|c|}{ Men } & \multicolumn{3}{|c|}{ Women } & \multicolumn{2}{|r|}{ Total } \\
\hline & $\begin{array}{l}\text { Population } \\
\text { at risk }\end{array}$ & $\begin{array}{l}\text { No. of } \\
\text { caces }\end{array}$ & $\begin{array}{c}\text { Prevalence } \\
(95 \% \mathrm{CI})\end{array}$ & $\begin{array}{l}\text { Population } \\
\text { at risk }\end{array}$ & $\begin{array}{c}\text { No. of } \\
\text { cases }\end{array}$ & $\begin{array}{c}\text { Prevalence } \\
(95 \% \mathrm{CI})\end{array}$ & $\begin{array}{c}\text { No. of } \\
\text { cases }\end{array}$ & $\begin{array}{c}\text { Prevalence } \\
(95 \% \mathrm{CI})\end{array}$ \\
\hline $0-39$ & 44,402 & 0 & 0 & 43,343 & 0 & 0 & 0 & 0 \\
\hline $40-49$ & 8,730 & 2 & $23(14-32)$ & 9,749 & 2 & $21(12-29)$ & 4 & $22(13-31)$ \\
\hline $50-59$ & 7,683 & 10 & $130(108-153)$ & 9,662 & 12 & $124(102-146)$ & 22 & $127(105-149)$ \\
\hline $60-69$ & 6,267 & 25 & $399(360-438)$ & 9,367 & 52 & $555(509-601)$ & 77 & $493(449-536)$ \\
\hline $70-79$ & 2,813 & 35 & $1,244(1,175-1,313)$ & 6,356 & 78 & $1,227(1,159-1,296)$ & 113 & $1,232(1,164-1,301)$ \\
\hline $80+$ & 1,244 & 16 & $1,286(1,216-1,356)$ & 3,624 & 38 & $1,049(985-1,112)$ & 54 & $1,109(1,044-1,175)$ \\
\hline Total & 71,139 & 88 & $124(102-146)$ & 82,101 & 182 & $222(193-251)$ & 270 & $176(150-202)$ \\
\hline Adjusted* & & & $154(130-178)$ & & & $153(128-177)$ & & $152(128-176)$ \\
\hline
\end{tabular}

*Age-adjusted to the Estonian general population in 1989.

Table 2. Ages-specific prevalence rates of PD (per 100,000)

The mean age of the patients with PD on the day of prevalence assessment was $71.4 \pm 8.8$ years with an age range of $41-95$ years: $70.4 \pm 9.7$ for men and $71.8 \pm 8.4$ for women, $71.4 \pm 8.7$ for urban and $71.3 \pm 9.2$ for rural people; $90 \%$ of the patients were over 60 years old. The mean duration of the disease was 5.1 years. The mean age at onset of symptoms was $66.9 \pm 10.1$ years with an age range from 34 to 86 years; $90 \%$ of the patients were over 52 years old. The differences in the mean age on prevalence day, in the mean age at onset of symptoms and in the duration of the disease between men and women, as also between urban and rural people were not statistically significant. The mean age of patients with other parkinsonian syndromes (63.3 years) was significantly lower than in patients with PD ( $\mathrm{p}=0.0004)$, as also the mean age at onset of the symptoms in patients with other parkinsonian syndromes (58.6 years) was significantly lower than with PD $(\mathrm{p}=0.0022)$.

The crude prevalence of PD in the Tartu district was 176 per 100,000 population, 177 for urban and 175 for rural inhabitants, 124 for men and 222 for women. After age adjustment to the Estonian general population, the prevalence of PD was 154 per 100,000 population, 159 for urban and 139 for the rural group, 154 for men and 153 for women (Table 1). Though the crude prevalence rates showed statistically significant female preponderance, the rates after age-adjustment reveal that there was no statistically significant difference between the age-adjusted prevalence rates of men versus women (relative risk 1.01). In the comparison of domiciles, the predominance of urban versus the rural population was no statistically significant (relative risk 1.15).

In distribution of patients with PD by age, the biggest group of patients $-41.8 \%-$ was in age 70-79 years. The age-specific prevalence increased from 22 per 100,000 population in the age group 40-49 years up to 1232 per 100,000 population in the age group 70-79 years (Table 2); $1.0 \%$ of population over the age of 65 years had PD. The 
association of age and age-specific prevalence analysed by Poisson model revealed significant increase of the risk of PD with advancing age $(\mathrm{p}=0.0001)$. The observed increase of prevalence rates with age showed an exponential relationship between these two variables (Fig. 2).

\section{Discussion}

The validity of prevalence estimates depends on complete patient identification and an enrolment that is related to the diagnostic criteria set used. The first aim of this study was to reach as complete a case ascertainment as

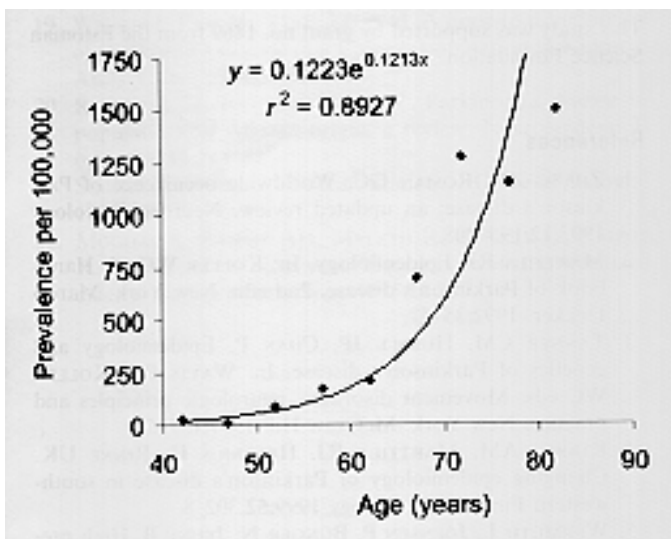

Figure 2. Regression analyses showing the increasing risk of PD with advancing age (exponential model).

possible with the highest diagnostic accuracy. We used all available sources and long time frames for patient findings. Data was regularly requested, during four years, from general practitioners, hospitals, nursing homes, the PD Society and the Sick Fund. All the patients were visited in the nursing homes for a more complete case identification.

Comparative studies have considered the relationship between prevalence rates and the diagnostic criteria of PD used (2-3, 29-31). The not-perfect diagnostic criteria set results with high percentage of false-positive cases, and too strict criteria produce falsenegative cases. The clinicopathological studies have shown a false-positive rate of PD of around $20 \%$, and a false-negative rate from 5 to $10 \%$, depending on patients selection (26, 31). For verification of PD in our study, we used the diagnostic criteria set of the United Kingdom Parkinson's Disease Society Brain Bank as the combination of criteria which obtains a high sensitivity and positive predictive value $(29,30)$. Several community studies have used the diagnostic criteria set that requires the presence of at least two cardinal signs from resting tremor, bradykinesia, rigidity and impaired postural reflexes for the diagnosis of PD $(10,14,16-19,30)$, or the UK PD Society criteria: the same set with the additional requirement that one sign must be bradykinesia $(4,8,12,15)$.

The study of a community sample has established the prevalence of PD in South Estonia to be 152 per 100,000 population, with a men versus women ratio of 1.01 and urban versus rural ratio 1.15. In most studies in Europe, the prevalence rates have been found to be higher than 100 per 100,000 population $(1-5,7-11,14,15)$.

A comparison of the prevalence rates of urban and rural people in the Tartu district shows an urban preponderance (Table 1) that is in the opposition with the latest studies in Finland and Norway $(4,7)$, but analogous with the urban versus rural ratio of 1.17 in Finland in 1971 (4). We found a significant urban predominance in the prevalence rates in the age groups 75-79 and 80-84 years, clearly in men, but also in women.

Rural residence has been suspected to be a risk factor of PD $(32,33)$. Several studies suggested that not rural residence but a specific feature of rural life such as pesticide or herbicide exposure could be distinguished and analysed as a risk factor of PD (34-36). Some studies showed an association between farming as an occupation and PD $(33,34)$, but others did not confirm that $(32,35)$. Kuopio et al. found that rural living, farming, or the use of herbicides and pesticides had no significant association with the risk of PD, but domestic animals, or something that is connected with the animals, may have a protective effect against PD (37). Marder et al. showed that there may be different environmental risk factors among different ethnic groups: rural living and farming were associated with PD only in African-Americans (38). In industrial areas, the findings suggested that the chronic exposure of occupational toxins and specific metals was associated with PD (39).

The use of pesticides is not extensive in Estonia and started later than in countries in Western Europe. If to presume that there is an association between PD and exposure to 
pesticides or herbicides, then it is expected that occurrence of PD in the rural population of Estonia could be similar to that in Western Europe decades ago. There is only a limited amount of data from the 1970ies comparing the prevalence among urban and rural people. In Finland, in 1971 the prevalence of urban versus rural population was 1.17 (4), which is comparable with results of urban predominance in our study (ratio 1.14). A conspicuous result shown in the Finnish study - a negative association between domestic animals at home and subsequent PD - could explain an additional factor causing the lower prevalence of PD in the rural Estonian people, who traditionally have domestic animals. On the other hand, the rural people has less occupational exposure to toxins and specific metals in industry suspected to be risk factors for PD (39).

PD appeared to be more common in men than in women in most studies $(1-9,11$, $12,15,19,30)$, but some studies revealed a women preponderance $(1,3,10,13,14,16$ 18). In our study the crude prevalence for women was significantly greater than for men (222 per 100,000 population for women and 122 for men), evidently because there were more older women than men in the population (Table 2). In Tartu county lived 153,240 inhabitants on January 1, 1996: 46.4\% men and 55.6\% women. Of all inhabitants, $19.4 \%$ were over 60 years old. In this age group, $34.8 \%$ were men and $65.2 \%$ were women. There is a specific demographic situation in Estonia: a twofold women preponderance in the older age groups due to a significantly longer average lifespan in women, and casualties of men in the Second World War. After the age standardization, the prevalence rates in men and women were similar (154 per 100,000 population in men and 153 per 100,000 population in women; ratio 1.01), and the difference was not significant.

In our study the age-specific prevalence rates increased with advancing age until the age group 80-84 years but decreased after the age of 85 . This upward trend was observed in most of the populations (1-3), with decreasing prevalence rates in the oldest age group $(4-6,8,9,12,15-18)$, or increasing prevalence in the very old in other studies $(7,10,11,13,14,19,30)$. In our study, 11 patients diagnosed with PD were older than 85 years; $10 \%$ of all patients with PD were older than 82 years. To identify as many patients as possible, particularly in older age group, all institutionalized people in the Tartu district were visited. Moghal et al. showed that institutionalized residents had double the prevalence rate compared to community residents (22). The functional disability in PD is progressive and later in the course of the illness a proportion of patients may become handicapped and require institutionalization. At the same time, the occurrence of PD in the most elderly may be unrecognised if they have no tremor, and there is risk of falsepositive cases due to high prevalence of essential tremor in older age. It has been noticed that more patients with a false diagnosis of PD were in the older age groups $(4,36)$. Fourteen patients with the diagnosis of PD lived in nursing homes in the Tartu district; in three of these cases, the diagnosis had not been previously made. Five patients in nursing homes with previous diagnosis of PD were excluded because they did not satisfy the diagnostic criteria of PD; four of them had essential tremor and one had another parkinsonian syndrome. The decline among the most elderly probably reflects poor ascertainment of the cases due to under-diagnosis in the oldest age group rather than an actual decrease in the disease prevalence.

When comparing the prevalence rates with other studies in the Caucasian populations in Europe, the rates are similar except for the slight urban preponderance but there was no statistically significant difference between the prevalence rates in urban and rural people. The differences in prevalence might be due to exposure to any environmental factors, but partially caused by the different medical referral habits in various segments of the population: the different referral pattern in rural compared with urban areas, in older- compared with younger-onset cases, in men compared with women, or in higher compared with lower socioeconomic status. 


\section{Acknowledgements}

This study was supported by grant No 1869 from the Estonian Science Foundation.

\section{References}

1. Zhang ZX, Roman GC. Worldwide occurrence of Parkinson's disease: An updated review. Neuroepidemiology 1993;12:195-208.

2. Marttila RJ. Epidemiology. In: Koller WC, ed. Handbook of Parkinson's disease. 2nd ed. New York: Marcel Dekker, 1992;35-57.

3. Tanner CM, Hubble JP, Chan P. Epidemiology and genetics of Parkinson's disease. In: Watts RL, Koller WC, eds. Movement disorders: Neurologic principles and practice. New York: McGraw-Hill 1997;137-52.

4. Kuopio AM, Marttila RJ, Helenius H, Rinne UK. Changing epidemiology of Parkinson's disease in southwestern Finland. Neurology 1999;52:302-8.

5. Wermuth L, Joensen P, Bünger N, Jeune B. High prevalence of Parkinson's disease in the Faroe Islands. Neurology 1997;49:426-32.

6. Fall PA, Axelson O, Fredriksson M, et al. Age-standardized incidence and prevalence of Parkinson's disease in Swedish community. J Clin Epidemiol 1996;49:637-41.

7. Tandberg E, Larsen JP, Nessler E, Riise T, Aarli JA. The epidemiology of Parkinson's disease in the county of Rogaland, Norway. Mov Disord 1995;10:541-9.

8. Sutcliffe RLG, Meara JR. Parkinson's disease epidemiology in the Northampton District, England. Acta Neurol Scand 1995;92:443-50.

9. Chio A, Magnani C, Schiffer D. Prevalence of Parkinson's disease in Northwestern Italy: Comparison of tracer methodology and clinical ascertainment of cases. Mov Disord 1998;13:400-5.

10. Beghi E, Monticelli ML, Sessa A, Simone P. The prevalence of parkinsonism in Italy: An epidemiological survey of the disease in general practice. Mov Disord 1994;9:403-8.

11. Dias JA, Felgueiras MM, Sanchez JP, Goncalves JM, Falcaeo JM, Pimenta ZP. The prevalence of Parkinson's disease in Portugal. Eur J Epidemiol 1994;10:763-7.

12. Mayeux R, Marder K, Cote LJ, et al. The frequency of idiopathic Parkinson's disease by age, ethnic group, and sex in Northern Manhattan, 1988-1993. Am J Epidemiol 1995;142:820-7.

13. Caradoc-Davies TH, Weatherall M, Dixon GS, Caradoc-Davies G, Hantz P. Is the prevalence of Parkinson's disease in New Zealand really changing? Acta Neurol Scand 1992;86:40-4.

14. Morgante L, Rocca WA, Di Rosa AE, et al. Prevalence of Parkinson's disease and other types of parkinsonism: A door-to-door survey in three Sicilian municipalities. Neurology 1992;42:1901-7.

15. Errea JM, Ara JR, Aibar C, de Pedro-Cuesta J. Prevalence of Parkinson's disease in Lower Aragon, Spain. Mov Disord 1999;14:596-604.

16. Kusumi M, Nakashima K, Harada H, Nakayama H, Takahashi K. Epidemiology of Parkinson's disease in Yonago City, Japan: Comparison with a study carried out 12 years ago. Neuroepidemiology 1996;15:201-7.

17. Moriwaka F, Tashiro K, Itoh K, et al. Prevalence of Parkinson's disease in Hokkaido, the northenmost island of Japan. Internal Medicin 1996;35:276-9.

18. Okada K, Kobayashi S, Tsunematsu T. Prevalence of Parkinson's disease in Izumo City, Japan. Gerontology 1990;36:340-4.

19. Wang SJ, Fuh JL, Teng EL, et al. A door-to-door survey of Parkinson's disease in a Chinese population in Kinmen. Arch Neurol 1996;53:66-71.

20. Richards M, Ray Chauduri K. Parkinson's disease in populations of African origin: A review. Neuroepidemiology 1996;15:214-21. 
21. Statistical Office of Estonia. Statistical yearbook. Tallinn, 1996.

22. Moghal S, Rajput AH, Meleth R, D'Arcy C, Rajput R. Prevalence of movement disorders in institutionalized elderly. Neuroepidemiology 1995;14:297-300.

23. Tison F, Dartigues JF, Dubes L, Zuber M, Alperovich A, Henry P. Prevalence of Parkinson's disease in elderly: A population study in Gironde, France. Acta Neurol Scand 1994;90:111-5.

24. Fahn S, Elton RL. Members of the UPDRS Development Committee. Unified Parkinson's Disease Rating Scale. In: Fahn S, Marsden CD, Calne DB, Lieberman A, eds. Recent developments in Parkinson's disease. Florham Park, NJ: Macmillan Health Care Information, 1987:153-63.

25. Hoehn MH, Yahr MD. Parkinsonism: onset, progression, and mortality. Neurology 1967; 17:427-42.

26. Gibb WRG, Lees AJ. The relevance of the Lewy body to the pathogenesis of idiopathic Parkinson's disease. J Neurol Neurosurg Psychiatry 1988;51:745-52.

27. Quinn N. Parkinsonism - recognition and differential diagnosis. Br Med J 1995;310:447-52.

28. Deuschl G, Bain P, Brin M. Consensus statement of the Movement Disorders Society on tremor. Mov Disord 1998;13(Suppl.3):2-23.

29. Anderson DW, Rocca WA, de Rijk MC, et al. Case ascertainment uncertainties in prevalence surveys of Parkinson's disease. Mov Disord 1998;13:626-32.

30. Melcon MO, Anderson DW, Vergara RH, Rocca WA. Prevalence of Parkinson's disease in Junin, Buenos Aires Province, Argentina. Mov Disord 1997;12:197-205.

31. Hughes AJ, Ben-Shlomo Y, Daniel SE, Lees AJ. What features improve the accuracy of clinical diagnosis in Parkinson's disease: A clinicopathologic study. Neurology 1992;42:1142-6.

32. Koller W, Vetere-Overfield B, Gray C, et al. Environmental risk factors in Parkinson's disease. Neurology 1990;40:1218-21.

33. Liou HH, Tsai MC, Chen CJ, et al. Environmental risk factors and Parkinson's disease: A case-controle study in Taiwan. Neurology 1997;48:1583-88.

34. Gorell JM, Johnson CC, Rybicki BA, Peterson EL, Richardson RJ. The risk of Parkinson's disease with exposure to pesticides, farming, well water, and rural living. Neurology 1998;50:1346-50.

35. Chan DKY, Woo J, Ho SC, et al. Genetic and environmental risk factors for Parkinson's disease in a Chinese population. J Neurol Neurosurg Psychiatry 1998;65:781-4.

36. Herzman C, Wiens M, Snow B, Kelly S, Calne D. A case-control study of Parkinson's disease in a horticultural region of British Columbia. Mov Disord 1994;9:69-75.

37. Kuopio AM, Marttila RJ, Helenius H, Rinne UK. Environmental risk factors in Parkinson's disease. Mov Disord 1999;14:928-39.

38. Marder K, Logroscino G, Alfaro B, et al. Environmental risk factors for Parkinson's disease in an urban mutiethnic community. Neurology 1998;50:279-81.

39. Gorell JM, Rybicki BA, Johnson CC, Peterson EL. Occupational metal exposures and the risk of Parkinson's disease. Neuroepidemiology 1999;18:303-8. 